\title{
Time course of serum C-reactive protein levels during induction chemoradiotherapy and its correlation with treatment response and survival in patients with advanced esophageal squamous cell carcinoma
}

\author{
HITOSHI FUJIWARA, ATSUSHI SHIOZAKI, AKINOBU FURUTANI, MASAYUKI YONEDA, TAKESHI KUBOTA, \\ SHUHEI KOMATSU, DAISUKE ICHIKAWA, KAZUMA OKAMOTO, YASUTOSHI MURAYAMA, \\ YOSHIAKI KURIU, HISASHI IKOMA, MASAYOSHI NAKANISHI, TOSHIYA OCHIAI and EIGO OTSUJI
}

Division of Digestive Surgery, Department of Surgery, Kyoto Prefectural University of Medicine, Kamigyo-ku, Kyoto 602-8566, Japan

Received December 7, 2012; Accepted March 1, 2013

DOI: $10.3892 / \mathrm{mco} .2013 .84$

\begin{abstract}
Preoperative serum C-reactive protein (CRP) levels have been shown to be of prognostic significance in patients with advanced esophageal carcinoma. However, the clinical significance of serum CRP levels in patients with unresectable or marginally resectable tumors in the absence of induction therapy has not been fully elucidated in relation to treatment response and prognosis. Thirty-four patients with clinical T3-T4 esophageal squamous cell carcinoma who underwent induction chemoradiotherapy (CRT) followed by esophagectomy were enrolled in this retrospective study. Serum CRP levels were measured during the course of CRT, i.e., prior to, during (1, 2, 3 and 4 weeks following initiation) and after CRT (prior to surgery). The association between CRP levels, CRT response and survival was analyzed. Elevated serum CRP levels exhibited a favorable decrease 2-3 weeks following CRT initiation in pathological responders and CRP $\leq 0.3 \mathrm{mg} / \mathrm{dl}$ at 2 and 3 weeks following CRT initiation, as well as prior to surgery, was significantly correlated with responders. In patients with pretreatment $\mathrm{CRP}>0.3 \mathrm{mg} / \mathrm{dl}(67.6 \%$ of patients in this study), CRP $\leq 0.3 \mathrm{mg} / \mathrm{dl}$ at 2 and 3 weeks following CRT initiation predicted responders with accuracies of 87.0 and $73.9 \%$, respectively. In the univariate survival analysis, CRP levels 3 weeks following CRT initiation, as well as CRP levels prior to surgery and pathological stage, were significant prognostic factors, although CRP levels prior to surgery was
\end{abstract}

Correspondence to: Dr Hitoshi Fujiwara, Division of Digestive Surgery, Department of Surgery, Kyoto Prefectural University of Medicine, 465 Kajii-cho, Kawaramachi-hirokoji, Kamigyo-ku, Kyoto 602-8566, Japan

E-mail: hfuji@koto.kpu-m.ac.jp

Key words: serum, C-reactive protein, chemoradiotherapy response, esophageal carcinoma the only independent prognostic factor in the multivariate analysis. Serum CRP levels during the course of CRT may be of prognostic and predictive significance for the CRT response in patients with unresectable or marginally resectable esophageal squamous cell carcinoma who undergo induction CRT.

\section{Introduction}

Esophageal carcinoma is highly malignant and the prognosis of patients with locally advanced tumors is poor. Preoperative chemoradiotherapy (CRT) has been shown to significantly improve survival in patients with advanced esophageal carcinoma. However, this survival benefit is limited to patients with a major pathological response (complete or subtotal tumor regression) (1). Prediction of the CRT response prior to or early during the course of CRT may be beneficial in avoiding or discontinuing this type of treatment in non-responders and may also help responders avoid invasive surgery through the initiation or continuation of CRT. Therefore, the identification of biomarkers that predict the CRT response is critical in multimodality treatment for advanced esophageal carcinoma.

Elevated serum C-reactive protein (CRP) levels have been shown to be associated with disease progression and poor prognosis in patients with esophageal carcinoma and preoperative serum CRP levels have been shown to be an independent prognostic factor in patients with resectable esophageal carcinoma (2-5). However, the clinical significance of serum CRP levels in patients with unresectable tumors in need of chemotherapy or CRT as an initial treatment has not been fully elucidated in relation to treatment response and prognosis.

In the present study, we investigated the association between pathological response and survival and the time course of serum CRP levels during induction CRT in patients with clinical T3-T4 esophageal squamous cell carcinoma, all of whom underwent subsequent esophagectomy. We also verified the usefulness of serum CRP levels as a potential biomarker in the prediction of the CRT response early in the course of induction CRT. 


\section{Patients and methods}

Patients. Thirty-four patients with clinical T3-T4 esophageal squamous cell carcinoma, who received induction CRT followed by esophagectomy at the Kyoto Prefectural University of Medicine Hospital between 2001 and 2008, were analyzed in this retrospective study. Induction CRT was indicated for unresectable or marginally resectable tumors, i.e., T4 or bulky T3 tumors that were considered difficult to completely resect in the absence of induction therapy. If a clinical response was observed and complete resection was thus considered possible, the patient was scheduled for surgery. Clinical and pathological staging was performed according to the tumornode-metastasis (TNM) classification of the International Union Against Cancer (UICC) (6). Esophagography, endoscopy, computed tomography and/or bronchoscopy were routinely performed to determine pretreatment clinical staging and treatment response. Endoscopic ultrasonography was occasionally performed. From 2004 onward, PET scans were performed prior to and following CRT. Written informed consent was obtained from all the patients.

Induction CRT. The induction CRT regimen consisted of radiation and concurrent administration of 5-fluorouracil (5-FU) and cisplatin, as previously described (7). Briefly, 5-FU was administered intravenously at $200-250 \mathrm{mg} / \mathrm{m}^{2} /$ day on days $1-5$, 8-12, 15-19 and 22-26 and cisplatin was administered at a dose of $5-7 \mathrm{mg} / \mathrm{m}^{2} /$ day by drip infusion for $1 \mathrm{~h}$ on days $1-5,8-12$, 15-19 and 22-26. In total, 40 Gy of radiation for 4 weeks at 2 Gy daily (5 days/week) was delivered. Treatment responses were evaluated 2-3 weeks following completion of CRT. Surgery was scheduled 4-6 weeks after the last day of CRT in patients for whom complete resection was considered feasible.

Surgical therapy and pathological response evaluation. The patients underwent subtotal esophagectomy with regional lymphadenectomy through right thoracotomy and laparotomy, followed by reconstruction using the stomach via a retrosternal route with cervical anastomosis through a neck incision. The pathological response to CRT was evaluated by the grade of response of the primary tumor. The complete tumor bed was cut into sections including the entire esophageal wall and grading of the response to CRT was as follows (8): grade 3 , complete disappearance of viable cancer cells in the tumor bed; grade 2,>2/3 disappearance of viable cancer cells; and grade $1,<2 / 3$ disappearance of viable cancer cells. CRT was considered effective in patients with grade 2 or 3 histological response (responders) and ineffective in patients with grade 1 histological response (non-responders).

Measurement of serum CRP. Serum CRP levels were measured in blood samples collected from each patient at the following six time points: prior to CRT (preCRT); 1, 2, 3 and 4 [-weeks after initiation of CRT (CRT1W, CRT2W, CRT3W and CRT4W, respectively); and prior to surgery (PreOP). Serum CRP levels were measured with a latex agglutination turbidimetric immunoassay (LZ-TEST 'Eiken' CRP-HG, Tokyo, Japan); normal serum levels were $\leq 0.3 \mathrm{mg} / \mathrm{dl}$.

Statistical analysis. In the correlation analysis between serum CRP levels and pathological response, continuous data
Table I. Patient characteristics.

Characteristic

Patient no. (total, 34)

Total
Gender
Male
Female
Age (years)
$<65$
$\geq 65$

Tumor location

$\mathrm{Ce}$

Ut

$\mathrm{Mt}$

$\mathrm{Lt}$

cStage

II

$$
4
$$

8

18

4

III 3

IV

cT

T3

$\mathrm{cN}$

NO

N1

$\mathrm{cM}$

M0

M1 (lym)

cCRT response

CR

PR

SD

pCRT response

Grade 1

Grade 2

Grade 3

ypStage

0

I 2

II 10

III 11

IV

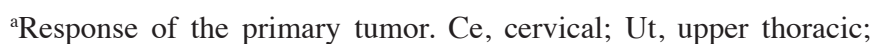
Mt, middle thoracic; Lt, lower thoracic; CRT, chemoradiotherapy.

were compared using the Mann-Whitney U test and ordinal data using the $\chi^{2}$ or Fisher's exact test. In survival analysis, data are shown as mean and range [95\% confidence interval (CI)]. Univariate survival analysis was performed using the Kaplan-Meier method with the log-rank test. Multivariate survival analysis and calculation of the odds ratios with $95 \%$ CI was performed using a Cox proportional hazard regression model, including all covariates that were identified as significant by univariate analysis. Statistical analyses were performed using software JMP version 8 for Macintosh (SAS 
Institute Inc., Cary, NC, USA). $\mathrm{P}<0.05$ was considered to indicate a statistically significant difference.

\section{Results}

Clinical characteristics of the study patients. The 34 patients analyzed in the present study were the same as those analyzed in our previous study (7). The background characteristics of the patients are listed in Table I. The patient sample consisted of 28 males and 6 females with a median age of 66.5 years. At pretreatment diagnosis, all primary tumors were classified as T3 $(47.1 \%)$ or T4 $(52.9 \%)$ and the majority of the patients $(79.4 \%)$ were classified as stage III. All M1 cases had distant lymph node metastases at the supraclavicular and celiac regions. At postoperative diagnosis, 8 primary tumors $(23.5 \%)$ were evaluated as grade 3 and pathological responses of primary tumors (grades 3 and 2) were observed in 18 patients $(52.9 \%)$. Complete resection was performed in 29 patients (85.3\%). No infective complications, such as pneumonia, were detected during the pretreatment evaluation and no infective adverse events, resulting in the discontinuation of CRT or the administration of antibiotics, were observed during CRT.

Association of serum CRP levels with pathological response. First, absolute values of CRP at each of the six time points during the course of induction CRT were compared according to the primary tumor response. No significant difference in pretreatment CRP values was observed between responders and non-responders, whereas responders exhibited significantly lower CRP values compared to those of non-responders at CRT2W, CRT3W and PreOP. There were no significant differences between CRP values at CRT1W and CRT4W (Fig. 1). Although pretreatment CRP values showed a tendency to decrease 2-3 weeks after the initiation of CRT in responders compared to non-responders, no significant differences were observed between CRP values prior to CRT and those at each subsequent time point. Subsequently, CRP levels ( $>0.3$ vs. $\leq 0.3$ ) at each of the 6 time points during the course of induction CRT were compared according to the primary tumor response (Table IIA). Pretreatment serum CRP levels were elevated (CRP $>0.3$ ) in 23 out of the 34 patients $(67.6 \%)$. Prior to CRT, no significant difference in CRP levels was observed between responders and non-responders, whereas responders exhibited significantly lower CRP levels $(\leq 0.3)$ compared to non-responders at CRT2W, CRT3W and PreOP. CRP levels at CRT1W and CRT4W were not different between the 2 groups. In addition, CRP levels (>0.3 vs. $\leq 0.3$ ) were compared according to the primary tumor response in patients with elevated pretreatment CRP levels (CRP $>0.3$ prior to CRT) (Table IIB). Responders exhibited significantly lower CRP levels $(\leq 0.3)$ compared to non-responders at CRT2W and CRT3W, whereas no significant difference was detected in CRP levels at CRT1W, CRT4W and PreOP between the 2 groups.

Prediction of pathological response by serum CRP levels. Prediction accuracies for pathological response by $C R P \leq 0.3$ at CRT2W, CRT3W and PreOP are shown in Table III. Among all 34 patients, CRP $\leq 0.3$ at CRT2W, CRT3W and PreOP predicted responders with accuracies of 76.5, 73.5 and 73.5\%, respectively. Furthermore, among patients with $\mathrm{CRP}>0.3$ at
Table II. Association of pathological CRT response with serum CRP levels.

\begin{tabular}{|c|c|c|c|}
\hline Parameter & $\begin{array}{l}\text { Responders } \\
\quad(\mathrm{n}=18)\end{array}$ & $\begin{array}{l}\text { Non-responders } \\
\qquad(\mathrm{n}=16)\end{array}$ & P-value \\
\hline \multicolumn{4}{|l|}{ PreCRT } \\
\hline $\mathrm{CRP} \leq 0.3$ & 7 & 4 & 0.477 \\
\hline $\mathrm{CRP}>0.3$ & 11 & 12 & \\
\hline \multicolumn{4}{|l|}{ CRT1W } \\
\hline $\mathrm{CRP} \leq 0.3$ & 8 & 6 & 0.681 \\
\hline $\mathrm{CRP}>0.3$ & 10 & 10 & \\
\hline \multicolumn{4}{|l|}{ CRT2W } \\
\hline $\mathrm{CRP} \leq 0.3$ & 14 & 4 & 0.005 \\
\hline $\mathrm{CRP}>0.3$ & 4 & 12 & \\
\hline \multicolumn{4}{|l|}{ CRT3W } \\
\hline $\mathrm{CRP} \leq 0.3$ & 14 & 5 & 0.014 \\
\hline $\mathrm{CRP}>0.3$ & 4 & 11 & \\
\hline \multicolumn{4}{|l|}{ CRT4W } \\
\hline $\mathrm{CRP} \leq 0.3$ & 10 & 6 & 0.291 \\
\hline $\mathrm{CRP}>0.3$ & 8 & 10 & \\
\hline \multicolumn{4}{|l|}{ PreOP } \\
\hline $\mathrm{CRP} \leq 0.3$ & 12 & 3 & 0.007 \\
\hline $\mathrm{CRP}>0.3$ & 6 & 13 & \\
\hline
\end{tabular}

B, Patients with pretreatment elevated CRP levels $(n=23)$.

\begin{tabular}{lccc}
\hline Parameter & $\begin{array}{c}\text { Responders } \\
(\mathrm{n}=11)\end{array}$ & $\begin{array}{c}\text { Non-responders } \\
(\mathrm{n}=12)\end{array}$ & P-value \\
\hline $\mathrm{CRT} 1 \mathrm{~W}$ & & & \\
$\mathrm{CRP} \leq 0.3$ & 2 & 10 & $>0.999$ \\
$\mathrm{CRP}>0.3$ & 9 & 1 & \\
$\mathrm{CRT} 2 \mathrm{~W}$ & & 11 & 0.001 \\
$\mathrm{CRP} \leq 0.3$ & 9 & & \\
$\mathrm{CRP}>0.3$ & 2 & 8 & 0.036 \\
$\mathrm{CRT} 3 \mathrm{~W}$ & & & \\
$\mathrm{CRP} \leq 0.3$ & 9 & 5 & 0.855 \\
$\mathrm{CRP}>0.3$ & 2 & 7 & \\
$\mathrm{CRT} 4 \mathrm{~W}$ & & & \\
$\mathrm{CRP} \leq 0.3$ & 5 & 1 & \\
$\mathrm{CRP}>0.3$ & 6 & 11 & \\
PreOP & & 5 & \\
$\mathrm{CRP} \leq 0.3$ & 5 & & \\
$\mathrm{CRP}>0.3$ & 6 & & \\
\hline
\end{tabular}

CRT, chemoradiotherapy; CRP, C-reactive protein.

PreCRT and CRP $\leq 0.3$ at CRT2W and CRT3W, predicted responders with accuracies of 87.0 and $73.9 \%$, respectively.

Association of serum CRP levels with survival. Results of univariate analysis of overall survival are shown in Table IV and Fig. 2. The mean survival time in all 34 patients was 17.2 months, with a 3 -year survival rate of $28.2 \%$. There were no significant differences in overall survival in terms of gender, age, tumor location, 
Table III. Prediction accuracies of pathological CRT response by serum CRP levels.

\begin{tabular}{lccccccc}
\hline & \multicolumn{3}{c}{ All patients $(\mathrm{n}=34)$} & & \multicolumn{2}{c}{ CRP $>0.3$ (PreCRT) patients $(\mathrm{n}=23)$} \\
\cline { 2 - 3 } Prediction responses & Sensitivity & Specificity & Accuracy & & Sensitivity & Specificity & Accuracy \\
\hline CRP $\leq 0.3$ & & & & & & \\
CRT2W & 77.8 & 75 & 76.5 & & 81.8 & 91.7 & 87 \\
CRT3W & 77.8 & 68.8 & 73.5 & & 81.8 & 66.7 & 73.9 \\
PreOP & 66.7 & 81.3 & 73.5 & & 45.5 & 91.7 & 69.6 \\
\hline
\end{tabular}

CRT, chemoradiotherapy; CRP, C-reactive protein.
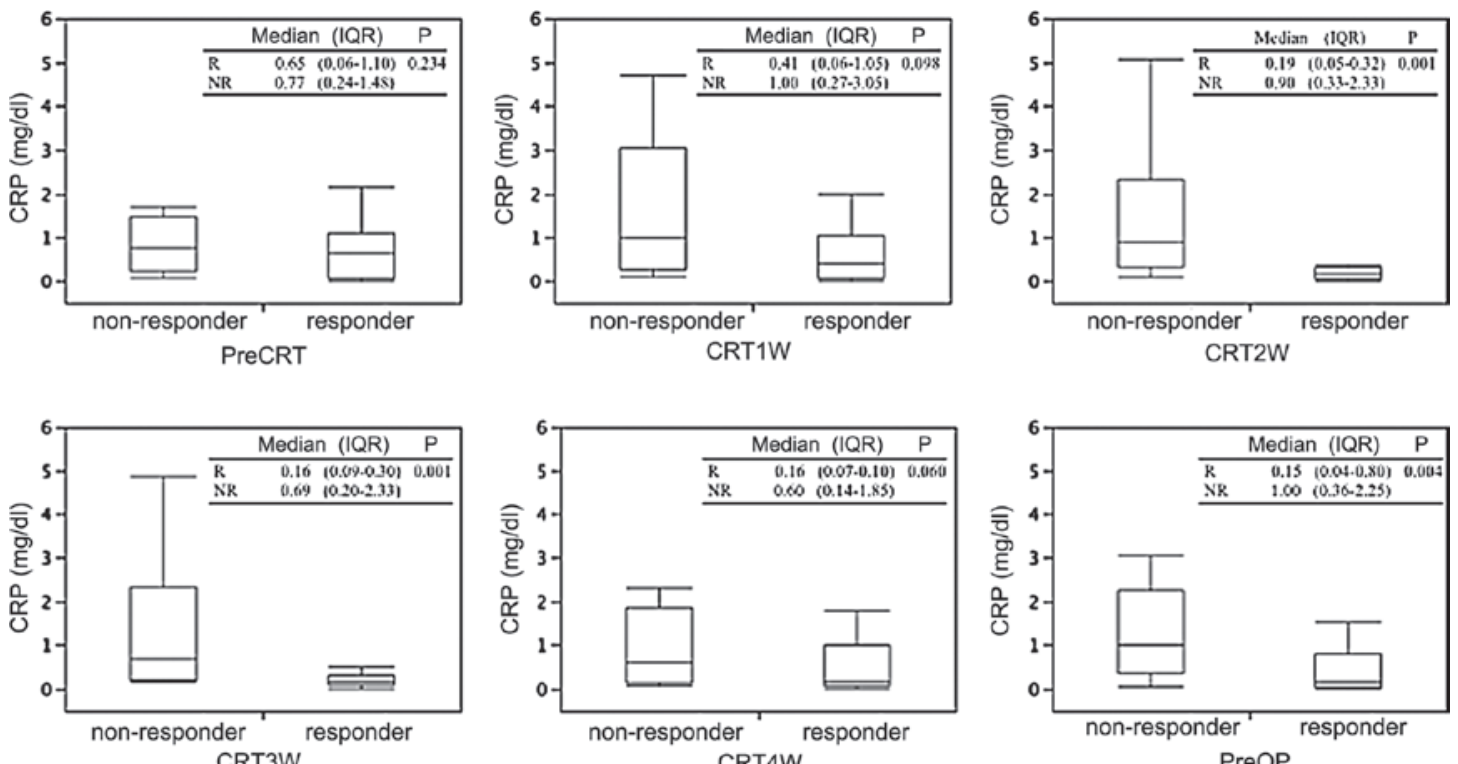

Figure 1. Relationship between the pathological chemoradiotherapy (CRT) response and serum C-reactive protein (CRP) levels during the course of induction CRT Significant differences between responders and non-responders were observed 2 and 3 weeks after CRT initiation (CRT2W and CRT3W) and preoperatively after CRT completion (PreOP). Lines, median values; bars, interquartile range; error bars, extreme values. R, responder, NR, non-responder, IQR, interquartile range.
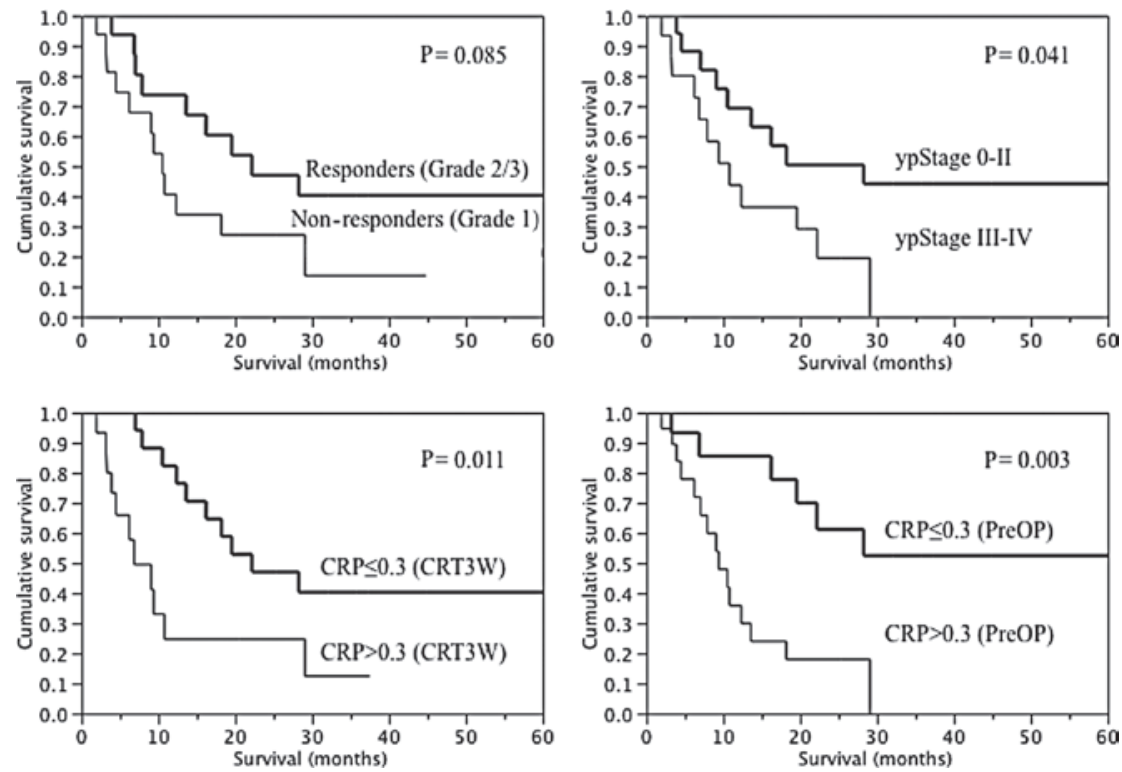

Figure 2. Kaplan-Meier survival curves according to pathological tumor factors and serum C-reactive protein (CRP) levels. In postoperative parameters, significant differences were observed in ypStage ( 0 -II vs. III-IV, $\mathrm{P}=0.041)$, whereas no differences were observed in the grade of the primary tumor response, although responders exhibited longer survival compared to non-responders. In preoperative parameters, significant differences were observed in serum CRP levels $(\mathrm{CRP} \leq 0.3$ vs. $\mathrm{CRP}>0.3) 3$ weeks after chemoradiotherapy (CRT) initiation (CRT3W, $\mathrm{P}=0.011$ ) and preoperatively after $\mathrm{CRT}$ completion (PreOP, $\mathrm{P}=0.003$ ). 
Table IV. Univariate analysis of overall survival according to clinicopathological parameters and serum CRP levels.

\begin{tabular}{|c|c|c|c|c|}
\hline Parameter & $\begin{array}{l}\text { Patients } \\
(n=34)\end{array}$ & $\begin{array}{l}\text { Mean survival } \\
\quad \text { (months) }\end{array}$ & $\begin{array}{l}\text { Mean survival } \\
\quad(95 \% \mathrm{CI})\end{array}$ & P-value \\
\hline
\end{tabular}

A, Clinicopathological parameters and overall survival.

\begin{tabular}{|c|c|c|c|c|}
\hline Overall & 34 & 17.2 & $12.1-22.3$ & \\
\hline \multicolumn{5}{|l|}{ Gender } \\
\hline Male & 28 & 16.1 & $10.5-21.7$ & \multirow[t]{2}{*}{0.148} \\
\hline Female & 6 & 22.2 & $5.3-39.0$ & \\
\hline \multicolumn{5}{|l|}{ Age (years) } \\
\hline$<65$ & 14 & 18.4 & $9.5-27.3$ & \multirow{2}{*}{0.622} \\
\hline$\geq 65$ & 20 & 16.1 & $9.7-22.6$ & \\
\hline \multicolumn{5}{|l|}{ Tumor location } \\
\hline Supracarinal & 12 & 14.1 & $5.7-22.5$ & \multirow[t]{2}{*}{0.378} \\
\hline Infracarinal & 22 & 18.9 & $12.0-25.7$ & \\
\hline \multicolumn{5}{|l|}{ cT } \\
\hline T3 & 16 & 18.4 & $13.1-23.7$ & \multirow[t]{2}{*}{0.401} \\
\hline $\mathrm{T} 4$ & 18 & 16.1 & $7.1-25.1$ & \\
\hline \multicolumn{5}{|l|}{$\mathrm{cN}$} \\
\hline NO & 9 & 19.3 & $1.8-36.9$ & \multirow[t]{2}{*}{0.730} \\
\hline N1 & 25 & 16.4 & $11.9-20.9$ & \\
\hline \multicolumn{5}{|l|}{ cStage } \\
\hline II+III & 30 & 17.9 & $12.2-23.6$ & \multirow[t]{2}{*}{0.128} \\
\hline IV & 4 & 12.0 & $1.0-24.9$ & \\
\hline \multicolumn{5}{|l|}{ cCRT response } \\
\hline $\mathrm{CR}+\mathrm{PR}$ & 18 & 18.8 & $12.5-25.1$ & \multirow[t]{2}{*}{0.104} \\
\hline SD & 16 & 13.3 & $3.4-23.2$ & \\
\hline \multicolumn{5}{|l|}{ ypStage } \\
\hline 0-II & 24 & 21.0 & $12.9-29.4$ & \multirow[t]{2}{*}{0.041} \\
\hline III-IV & 10 & 12.2 & 7.2-17.1 & \\
\hline \multicolumn{5}{|l|}{ pCRT response } \\
\hline Responders (grades 2+3) & 18 & 20.6 & $12.5-28.8$ & \multirow[t]{2}{*}{0.085} \\
\hline Non-responders (grade 1) & 16 & 13.3 & 7.1-19.6 & \\
\hline
\end{tabular}

B, CRP levels and overall survival.

\begin{tabular}{|c|c|c|c|c|}
\hline Parameter & $\begin{array}{l}\text { Patients } \\
(n=34)\end{array}$ & $\begin{array}{l}\text { Mean survival } \\
\text { (months) }\end{array}$ & $\begin{array}{l}\text { Mean survival } \\
(95 \% \mathrm{CI})\end{array}$ & P-value \\
\hline \multicolumn{5}{|l|}{ PreCRT } \\
\hline $\mathrm{CRP} \leq 0.3$ & 11 & 23.1 & $10.8-35.4$ & \multirow[t]{2}{*}{0.054} \\
\hline $\mathrm{CRP}>0.3$ & 23 & 14.3 & $9.2-19.5$ & \\
\hline \multicolumn{5}{|l|}{ CRT1W } \\
\hline $\mathrm{CRP} \leq 0.3$ & 14 & 18.9 & $8.9-29.4$ & \multirow[t]{2}{*}{0.194} \\
\hline $\mathrm{CRP}>0.3$ & 20 & 16.0 & $10.0-21.9$ & \\
\hline \multicolumn{5}{|l|}{ CRT2W } \\
\hline $\mathrm{CRP} \leq 0.3$ & 18 & 19.8 & $11.9-27.6$ & \multirow[t]{2}{*}{0.256} \\
\hline $\mathrm{CRP}>0.3$ & 16 & 14.3 & $7.3-21.3$ & \\
\hline \multicolumn{5}{|l|}{ CRT3W } \\
\hline $\mathrm{CRP} \leq 0.3$ & 19 & 22.6 & $15.2-30.0$ & \multirow[t]{2}{*}{0.011} \\
\hline $\mathrm{CRP}>0.3$ & 15 & 10.3 & $4.5-16.1$ & \\
\hline \multicolumn{5}{|l|}{ CRT4W } \\
\hline $\mathrm{CRP} \leq 0.3$ & 16 & 23.5 & $14.9-32.1$ & \multirow[t]{2}{*}{0.066} \\
\hline $\mathrm{CRP}>0.3$ & 18 & 11.6 & $6.2-17.0$ & \\
\hline \multicolumn{5}{|l|}{ PreOP } \\
\hline $\mathrm{CRP} \leq 0.3$ & 15 & 25.0 & $15.5-34.5$ & \multirow{2}{*}{0.003} \\
\hline $\mathrm{CRP}>0.3$ & 19 & 11.0 & $6.9-15.1$ & \\
\hline
\end{tabular}

CRT, chemoradiotherapy; CRP, C-reactive protein; PreOP, prior to surgery; CI, confidence interval; CR, complete response; PR, partial response; $\mathrm{SD}$, stable disease. 
Table V. Multivariate analysis of overall survival.

\begin{tabular}{lccc}
\hline & P-value & Odds ratio & $95 \% \mathrm{CI}$ \\
\hline $\begin{array}{c}\text { ypStage } \\
0 \text {-II/III-IV }\end{array}$ & 0.659 & 0.80 & $0.28-2.20$ \\
$\begin{array}{c}\text { CRP }(\mathrm{CRT} 3 \mathrm{~W}) \\
\leq 0.3 />0.3\end{array}$ & 0.124 & 0.46 & $0.17-1.24$ \\
$\begin{array}{l}\mathrm{CRP}(\mathrm{PreOP}) \\
\leq 0.3 />0.3\end{array}$ & 0.021 & 0.31 & $0.10-0.84$ \\
\hline
\end{tabular}

CRP, C-reactive protein; CRT, chemoradiotherapy; PreOP, prior to surgery.

cTNM classification, or clinical response to CRT. Regarding the grade of the primary tumor response, although the result was not significant, responders tended to survive longer compared to non-responders. Significant differences were observed in ypStage (0-II vs. III-IV) (Table IVA). Furthermore, in relation to serum CRP levels, significantly longer survival was observed in $\mathrm{CRP} \leq 0.3$ patients compared to $\mathrm{CRP}>0.3$ patients at $\mathrm{CRT} 3 \mathrm{~W}$ and PreOP. Although the result was not significant at PreCRT and CRT4W, CRP $\leq 0.3$ patients tended to survive longer compared to CRP $>0.3$ patients. No significant difference was observed at CRT1W and CRT2W (Table IVB). In multivariate analysis, preoperative $\mathrm{CRP} \leq 0.3$ was identified as the only independent prognostic factor (Table $\mathrm{V}$ ).

\section{Discussion}

In the present study, we investigated the association between serum CRP levels, pathological CRT response and prognosis in patients with unresectable or marginally resectable tumors who underwent induction CRT followed by esophagectomy, with a focus on temporal changes in CRP levels during CRT (not prior to or after CRT) and demonstrated that serum CRP levels measured shortly after CRT initiation correlated with CRT response and prognosis.

Elevated serum CRP levels have been shown to be associated with disease progression and poor prognosis in patients with esophageal carcinoma $(2-5,9,10)$. However, the underlying mechanisms by which CRP levels are associated with disease progression or prognosis have not been fully elucidated. In a previous study, we included the same patients as the present study and demonstrated that elevated serum CRP levels after CRT completion (prior to surgery), but not prior to CRT initiation, correlated with a poor CRT response and prognosis in close association with IL-6 levels in serum and local tumor tissues and that IL- 6 and other cytokines or growth factors secreted by tumor tissues through tumor-stromal or tumorhost interactions may play a critical role in the elevation of serum CRP levels and poor clinical outcome (7).

The significant correlation between postoperative pathological tumor parameters and prognosis has been well characterized and the grade of the primary tumor response has a prognostic significance $(10,11)$, as does pathological stage $(1,12-14)$. In the present study, among postoperative parameters, pathological stage was significantly correlated with prognosis, whereas the primary tumor response was not identified as a significant prognostic factor. Several factors, such as the limited patient sample and the nodal status may have affected the results. It is noteworthy that preoperative serum CRP levels, after CRT completion (prior to surgery), as well as during CRT (3 weeks after CRT initiation), have a superior prognostic impact over postoperative pathological tumor parameters in multivariate analysis.

As regards the correlation between CRP and the CRT response, pretreatment elevated CRP values exhibited a clear tendency to decrease 2-3 weeks following CRT initiation in responders, which strongly suggests that CRP levels may decrease according to CRT-induced tumor reduction in responders. Furthermore, CRP values exhibited a poor tendency to decrease in non-responders. In this regard, CRT-induced increases in activated NF- $\mathrm{\kappa B}$ in tumor tissues have been shown to be associated with a poor CRT response and prognosis in patients who underwent preoperative CRT $(15,16)$. NF- $\mathrm{kB}$ is a transcription factor that is highly involved in cancer progression and inflammatory response regulation (17). CRP may reflect the tumor status associated with CRT resistance in non-responders.

Significant differences between responders and non-responders were observed in both absolute CRP values and relative CRP levels (CRP $\leq 0.3$ vs. $C R P>0.3$ ) at identical time points (CRT2W, CRT3W and PreOP). From the viewpoint of a simple and easy evaluation, the comparison of relative CRP levels and not absolute CRP values is considered suitable for predicting the CRT response. In addition, we investigated the relationship between CRP levels and the CRT response according to pretreatment CRP levels. As a result, among all patients, the prediction accuracy of CRP levels for responders was not as significant $(76.5 \%$ at CRT2W), whereas in patients with pretreatment CRP $>0.3$, the prediction accuracy for responders increased to up to $87 \%$. By contrast, CRP $\leq 0.3$ at PreOP was a significant predictor for responders in all patients, whereas it was not in patients with pretreatment $\mathrm{CRP}>0.3$. The presence of responders among patients with pretreatment CRP $\leq 0.3$ is considered to have affected prediction accuracy. Pretreatment baseline CRP levels induced by tumor progression and the CRP-mediated tumor response to CRT may determine the ability of serum CRP levels to predict the CRT response.

Furthermore, no significant correlation was observed between CRP levels at CRT4W and the CRT response. The frequency of adverse events, such as bone marrow suppression and radiation-induced esophagitis, increased during the time course of CRT among the patients assessed in this study (data not shown). Tumor-derived decreases in CRP levels may have been masked by adverse event-derived inflammation, resulting in a reduction in the predictive accuracy of CRP at CRT4W.

In conclusion, the present study has demonstrated that serum CRP levels during CRT were closely associated with the pathological CRT response and prognosis and, particularly in patients with elevated CRP prior to CRT, a decrease in CRP within normal ranges 2-3 weeks following CRT initiation predicted a favorable pathological response with the highest accuracy. Despite the small patient sample and retrospective nature of the present study, our results suggested that serum CRP may provide additional predictive information to conventional imaging studies for early modification of the treatment protocol during CRT in advanced esophageal squamous cell 
carcinoma. The utility of serum CRP for early prediction of the CRT response may be determined by a well-designed prospective study.

\section{References}

1. Gebski V, Burmeister B, Smithers BM, Foo K, Zalcberg J and Simes J: Survival benefits from neoadjuvant chemoradiotherapy or chemotherapy in oesophageal carcinoma: a meta-analysis. Lancet Oncol 8: 226-234, 2007.

2. Nozoe T, Saeki H and Sugimachi K: Significance of preoperative elevation of serum C-reactive protein as an indicator of prognosis in esophageal carcinoma. Am J Surg 182: 197-201, 2001.

3. Ikeda M, Natsugoe S, Ueno S, Baba M and Aikou T: Significant host- and tumor-related factors for predicting prognosis in patients with esophageal carcinoma. Ann Surg 238: 197-202, 2003.

4 Shimada H, Nabeya Y, Okazumi S, et al: Elevation of preoperative serum C-reactive protein level is related to poor prognosis in esophageal squamous cell carcinoma. J Surg Oncol 83: 248-252, 2003.

5. Crumley AB, McMillan DC, McKernan M, Going JJ, Shearer CJ and Stuart RC: An elevated C-reactive protein concentration, prior to surgery, predicts poor cancer-specific survival in patients undergoing resection for gastro-oesophageal cancer. $\mathrm{Br} \mathrm{J}$ Cancer 94: 1568-1571, 2006.

6. Sobin LH and Wittekind CH (eds): UICC TNM Classification of Malignant Tumors. 6th edition. Wiley-Liss, New York, NY, pp60-64, 2002.

7. Fujiwara H, Suchi K, Okamura S, et al: Elevated serum CRP levels after induction chemoradiotherapy reflect poor treatment response in association with IL-6 in serum and local tumor site in patients with advanced esophageal cancer. J Surg Oncol 103 62-68, 2011.
8. Japan Esophageal Society: Japanese Classification of Esophageal Cancer. 10th edition. Kanehara, Tokyo, 2008.

9. Deans DA, Wigmore SJ, Gilmour H, Paterson-Brown S, Ross JA and Fearon KC: Elevated tumour interleukin-lbeta is associated with systemic inflammation: a marker of reduced survival in gastro-oesophageal cancer. Br J Cancer 95: 1568-1575, 2006.

10. Kobayashi T, Teruya M, Kishiki T, et al: Inflammation-based prognostic score, prior to neoadjuvant chemoradiotherapy, predicts postoperative outcome in patients with esophageal squamous cell carcinoma. Surgery 144: 729-735, 2008.

11. Yano M, Tsujinaka T, Shiozaki H, et al: Concurrent chemotherapy (5-fluorouracil and cisplatin) and radiation therapy followed by surgery for T4 squamous cell carcinoma of the esophagus. J Surg Oncol 70: 25-32, 1999.

12. Chirieac LR, Swisher SG, Ajani JA, et al: Posttherapy pathologic stage predicts survival in patients with esophageal carcinoma receiving preoperative chemoradiation. Cancer 103: 1347-1355, 2005.

13. Berger AC, Farma J, Scott WJ, et al: Complete response to neoadjuvant chemoradiotherapy in esophageal carcinoma is associated with significantly improved survival. J Clin Oncol 23: 4330-4337, 2005.

14. de Manzoni G, Pedrazzani C, Pasini F, et al: Chemoradiotherapy followed by surgery for squamous cell carcinoma of the thoracic esophagus with clinical evidence of adjacent organ invasion. J Surg Oncol 95: 261-266, 2007.

15. Karin M: Nuclear factor-kappaB in cancer development and progression. Nature 441: 431-436, 2006.

16. Izzo JG, Malhotra U, Wu TT, et al: Association of activated transcription factor nuclear factor kappaB with chemoradiation resistance and poor outcome in esophageal carcinoma. J Clin Oncol 24: 748-754, 2006.

17. Izzo JG, Wu X, Wu TT, et al: Therapy-induced expression of NF-kappaB portends poor prognosis in patients with localized esophageal cancer undergoing preoperative chemoradiation. Dis Esophagus 22: 127-132, 2009. 